\title{
Efectos colaterales de la pandemia: el impacto del COVID-19 en los derechos culturales. Reciente postura de la relatora especial de Naciones Unidas en su informe de 17 de febrero de 2021
}

Collateral effects of the pandemic: the impact of COVID-19 on cultural rights. Recent position of the UN Special Rapporteur in her report of 17 February 2021

\section{ELISABET CUETO SANTA EUGENIA}

Doctoranda en Derecho Procesal

Universidad de Oviedo (España)

cuetosantaeugenia@gmail.com

Por todos es sabido que la cultura es el motor del crecimiento de una sociedad, y es por ello que los derechos culturales - especialmente los que atañen a minorías, debido a la importancia de preservar su legado cultural específico y valioso- han de ser resguardados y protegidos. Es por esta razón que existe la figura de la relatoría especial de Naciones Unidas en la esfera de los derechos culturales, cuyo mandato se inició en el año 2009 y se ha ido renovando y manteniendo desde entonces ${ }^{1}$.

Cuando el pasado año estalló la pandemia sanitaria de la COVID-19, la relatora especial llevó a cabo un análisis acerca del modo en que esta crisis afectaba a los derechos culturales, llegando a la conclusión de que los derechos culturales se estaban viendo perjudicados de forma clara y directa. Tras llevar a cabo un estudio y análisis ${ }^{2}$, la relatora

Cómo citar este trabajo: CUETO SANTA EUGENIA, Elisabet, "Efectos colaterales de la pandemia: el impacto del COVID-19 en los derechos culturales. Reciente postura de la relatora especial de Naciones Unidas en su informe de 17 de febrero de 2021", Revista de Estudios Jurídicos y Criminológicos, n. ${ }^{\circ} 4$, Universidad de Cádiz, 2021, pp. 263-266, DOI: https://doi.org/10.25267/REJUCRIM.2021.i.4.10

1 Vid. Página web del mandato de la Relatora Especial en la esfera de los derechos culturales: https://www.ohchr.org/sp/issues/culturalrights/pages/srculturalrightsindex.aspx , visitada por última vez el 2 de julio de 2021.

${ }^{2}$ En estrecha relación con esto, cabe mencionar que con posterioridad a la publicación del informe al que esta crónica hace referencia, la relatora elaboró un cuestionario con la intención de continuar analizando el impacto de la COVID-19 en los derechos culturales a nivel global. Dicho cuestionario fue difundido entre diversos gobiernos estatales y regionales, autoridades locales, organizaciones internacionales y nacionales, instituciones nacionales de derechos humanos, organismos de igualdad y organizaciones de la sociedad 
publicó el informe al que la presente crónica hace referencia ${ }^{3}$, que tiene una relevancia importantísima: la pandemia ha cercenado gran cantidad de derechos y los relativos a la cultura no han sido en absoluto una excepción.

El presente informe hace hincapié en el impacto de la COVID-19 en los derechos culturales, especialmente de las minorías o pueblos indígenas que en muchos casos se han visto marginalizados y condenados al ostracismo, padeciendo consecuencias fatales. En la introducción del informe, se hace referencia a la interconexión existente entre todos los derechos humanos y la importancia de velar por la garantía de todos ellos, estableciendo la correlación entre la crisis sanitaria y la falta de derechos culturales en múltiples casos.

De este modo, se mencionan de forma sucinta una serie de artistas y músicos irremplazables que han fallecido durante la pandemia, se hace mención a la importante crisis económica que ha llevado a la bancarrota a industrias musicales, artísticas, museos, el cierre de los espectáculos en vivo, etc. Para contrarrestar esto, se hace referencia a las nuevas formas de arte, eventos y entretenimiento de manera telemática, incluyendo entre estos los encuentros artístico-religiosos. Esto es a su vez problemático: no deja de ser un factor que abre más la brecha de la desigualdad previamente existente, dado que todas aquellas personas sin recursos económicos para tener una conexión a internet o un ordenador han quedado mucho más descolgados y apartados de lo que ya estaban.

En el tercer apartado del informe se hace referencia al papel específico de la cultura durante la pandemia, estableciéndose la importancia de las artes como vital a la hora de prevenir riesgos de salud tanto física como mental. También se hace alusión a la manera de lidiar con los problemas de acceso a la cultura por parte de diversos estados. De este modo comprendemos que también esta cuestión ha sido desigual, dado que no todos los países han respondido de la misma manera - el informe dice en su párrafo número 36 que, dado que no todos los países disponen de la misma cantidad de recursos para hacer frente a la crisis, deberían desarrollarse herramientas o mecanismos que permitiesen coordinar esfuerzos entre estados, de cara a que la solidaridad a este respecto pueda ser global-.

En aras de dotar de una nota alegre al informe, se establece una relación de obras y manifestaciones artísticas inspiradas por la pandemia, haciendo hincapié en la importancia de emplear el arte no únicamente como medio para mostrar belleza, sino también como herramienta de cohesión social capaz de ayudar a la población a superar una crisis tan grave como la supuesta por la COVID-19. En este sentido, se establece que las crisis tienen potencial positivo de cara a fortalecer la cultura y los derechos culturales, permitiendo que se encuentren soluciones a dichas crisis de una forma respetuosa con los derechos humanos y que, de este modo, se fomente la resiliencia.

civil, entre otros interesados en el mes de mayo de 2020. Al respecto Vid. Página web del Informe, Apartado de Metodología:

https://www.ohchr.org/SP/Issues/CulturalRights/Pages/Covid19.aspx , visitada por última vez el 2 de julio de 2021.

${ }^{3}$ Vid. Informe del año 2021 de la Relatora Especial de Naciones Unidas en la esfera de los derechos culturales: "Impacto de la pandemia de COVID- 19 en las culturas y los derechos culturales, A/HRC/46/34, de 17 de febrero de 2021". Página web: https://undocs.org/es/A/HRC/46/34, visitada por última vez el 2 de julio de 2021. 
El cuarto apartado del informe aborda un asunto peliagudo: el derecho a la ciencia. En este sentido, la relatora indica que parte de su mandato establece el derecho a beneficiarse del progreso científico y sus aplicaciones, así como de la libertad científica. Es aquí donde menciona problemáticas que han supuesto verdaderos conflictos durante la pandemia, tales como el negacionismo del virus, los mitos falsamente propagados en relación con cuestiones inherentes a la pandemia, o la desigualdad a la hora de asegurarse dosis de vacunación para según qué países. En relación con la apertura de la ciencia y la igualdad de derechos a la hora de acceder a la misma, la relatora establece la necesidad de profundizar y realizar un informe específico, para lo cual emplaza a la UNESCO.

Los apartados quinto y sexto establecen los pasos necesarios a seguir para mitigar el impacto de la COVID-19 en los derechos culturales y la infraestructura internacional existente con la que contamos para lograrlo: el Pacto Internacional de Derechos Económicos, Sociales y Culturales, el Pacto Internacional de Derechos Civiles y Políticos, la Declaración Universal de Derechos Humanos, las diversas publicaciones del Comité Económico Social y Cultural de las Naciones Unidas, los Objetivos de Desarrollo Sostenible, etc.

Para mitigar el impacto de la COVID-19 en la cultura y los derechos de esta índole resulta absolutamente necesario que los Estados inviertan en tanto en su cultura y ciencia como en sus artistas y científicos. Para ello resultaría interesante que se dotara de financiación pública a los sectores artísticos y culturales. La UNESCO se ha pronunciado a este respecto, recomendando a los gobiernos que inviertan más en la cultura ${ }^{4}$. Esto ha sido respaldado por diversos grupos de la sociedad civil, que están ejerciendo presión para que parte de los fondos de los paquetes de medidas de recuperación frente a la COVID-19 se destinen a estos efectos ${ }^{5}$. El informe de la relatora, además, hace hincapié en la necesidad de promover una perspectiva que tenga en cuenta los derechos culturales, no solo a nivel estatal de cada país, sino también de forma interconectada en una suerte de plan cultural global.

El informe finaliza con una serie de conclusiones y recomendaciones que serían a todas luces útiles si los Estados realizasen el esfuerzo de seguirlas. En este sentido, destacan la garantía del acceso a la ciencia, la protección de todas las manifestaciones artísticas, el esfuerzo por reabrir instituciones culturales y establecer relaciones, mecanismos y métodos de colaboración entre las mismas, cubrir gastos de la cultura estatal — evitando realizar recortes a los presupuestos de esta-, y asegurar libertad artística y científica para todos aquellos artistas y científicos que carecen de ella.

En general, el presente informe expone de manera clara y concisa todas aquellas cuestiones relativas al ámbito de los derechos culturales que se han visto afectados de

\footnotetext{
${ }^{4}$ De hecho, la UNESCO publicó una guía práctica de cara a fortalecer la cultura ante la crisis sanitaria y construir políticas de resiliencia para que el acceso a la cultura se vea lo menos afectado posible por la pandemia. Vid. La cultura en crisis: guía de políticas para un sector creativo resiliente, UNESCO, 2020. Libro en acceso libre en la página web de la UNESCO:

https://unesdoc.unesco.org/ark:/48223/pf0000374633.locale=en, página visitada por última vez el 2 de julio de 2021.

${ }^{5}$ Cfr. Informe de la de la Relatora Especial de Naciones Unidas en la esfera de los derechos culturales, cit., Párrafo 54.
} 
manera negativa por la pandemia, haciendo un análisis pormenorizado no solamente de aquellas cuestiones que resultan problemáticas, sino también de posibles modos de contrarrestar o combatir esos problemas. Para ello, se preocupa de narrar posibles pasos a seguir y exponer los instrumentos internacionales que salvaguardan los distintos aspectos a los que el informe hace referencia.

En resumen, el instrumento referenciado en la presente crónica constituye una herramienta valiosa que, de ser seguida por los Estados miembros de Naciones Unidas, devendría de manera muy positiva en la garantía de los derechos culturales a nivel mundial. 